\title{
Federico Gamboa
}

Hace un año, al celebrarse el Primer Congreso Internacional de Catedráticos de Literatura Iberoamericana, que dió origen al Instituto que tiene por expresión esta Revista, la Academia Mexicana correspondiente de la Española dedicó una sesión solemne a los congresistas en el Paraninfo de la Universidad Nacional de México. Presidió la sesión y dió la bienvenida a los miembros que habían participado en la asamblea, don Federico Gamboa, ilustre director de la Academia. Su figura esbelta $\mathrm{y}$ fina, su cabeza de pelo ralo y totalmente emblanquecido, se destacaba sobre el fondo obscuro del retablo que sirve de fondo a la mesa rectoral. Dijo palabras de cordialidad, castizas como todo lo que salía de su pluma, a los colegas que venían de otros países y que eran académicos también de instituciones hermanas, como Brenes-Mesén, García-Prada, Balseiro; se refirió a los demás congresistas en tono de íntima amistad y de elevada camaradería. Fuera de la sesión, en charla íntima derrochó el ingenio que todos saboreaban en su conversación. Para cada uno tuvo la frase precisa, el recuerdo vivaz, la discreta alusión, la ironía feliz. Al despedirse, los que le conocían de otros tiempos tuvieron la impresión de haber encontrado al amigo como lo habían dejado años atrás, con el corazón siempre dispuesto a derrochar sus más preciados dones, la inteligencia alerta y el ingenio presto. Los que por primera vez le trataban se enorgu- 
llecían de haber conocido a uno de los espíritus más nobles del México de los últimos tiempos. El caballero de rancia estirpe estaba ahí, tendiendo la mano, sonriente, la mirada traviesa, la noble frente nimbada ya por el respeto y la admiración de propios y extraños.

Como director de la Academia se empeñó, más tarde, en que prosperara la iniciativa de otorgar diplomas a quienes se han distinguido en las dos Américas por su labor en pro de la lengua y la literatura iberoamericana. El último acto de su gestión ha sido, tal vez, este de enaltecer la obra de los profesores que han puesto su vida al servicio de la cultura hispánica. La Academia Mexicana extendía su radio de acción a países de otra lengua, pero vinculados estrechamente con la tradición de nuestra raza.

Ahora, don Federico Gamboa ha muerto. Unos días antes se mostraba particularmente interesado en la participación de la Academia en los homenajes que México iba a tributar a don Juan Ruiz de Alarcón en el tercer centenario de su muerte. Personalmente, dictaba la inscripción que habrá de llevar la talla en madera que la Academia obsequia a la Universidad para que la fije en su Paraninfo. Presidía la sesión con la misma dignidad afectuosa, cordial, que le era natural en todos los actos de su vida. Al despedirse de él, los académicos tuvieron, sin embargo, la sensación de que estaban contados los días del gran escritor. Catorce días solamente sobrevivía a este último acto de su vida literaria.

Por derecho propio era considerado el patriarca de las letras mexicanas. Con Carlos Díaz Dufoo, con Balbino Dávalos, formó parte de uno de los grupos más brillantes que han producido las letras de México. Hace apenas unos meses, se festejó su jubileo literario por la publicación del primer libro - Del natural- allá por el año de I888. El mismo nombre de la obra nos da ya el del casillero en que él mismo quiso colocarse para su clasificación en la literatura nacional. Discípulo de Zola y de los 
Goncourt, nunca negó su filiación literaria, aunque otra haya sido, andando el tiempo, su doctrina social y religiosa.

Viajó en su juventud por tierras de América y Europa. Gustó de toḍos los frutos que la vida ofrenda; pero supo también, a tiempo, recogerse en sí mismo y hacer de su existencia ejemplo para los demás. A veces hay en su vida extrañas paradojas: el México revolucionario, por ejemplo, lo anatematizó como a uno de los que más fielmente representaban el pasado, $\mathrm{y}$, sin embargo, ningún escritor afín a la Revolución ha escrito un drama como La venganza de la gleba, que puede ser considerado como obra radicalmente revolucionaria no obstante haber sido producida en una época en que solamente unos cuantos se atrevían a decir ciertas cosas que ahora se gritan, sin peligro, a los cuatro vientos. Hondo impulso de renovación se desprende de Santa, de La llaga, y de Suprema ley. Con todas las limitaciones que presupone el "naturalismo" en literatura, Gamboa es, sin duda, uno de los más grandes escritores que han alentado bajo su égida.

Setenta y cuatro años vivió el noble artista. Del 22 de diciembre de I864 al I5 de agosto de 1939, discurrió una vida íntegramente vivida. Juventud bohemia, como era natural en una época en que predominaba en los hombres de letras la influencia de una Francia pecadora y artista ; madurez laboriosa al servicio del país en misiones diplomáticas desempeñadas con decoro, y en difíciles circunstancias, con acendrado patriotismo; vejez austera de hidalgo venido a menos en lo que a bienes materiales se refiere; pero cada vez más opulento en dones del espíritu; muerte tranquila, sin sobresaltos, como de quien sabe lo que ha cosechado en la vida y lo que deja de ejemplo y de ternura a los demás.

México va perdiendo, uno a uno, a los hombres que dejaron a su tiempo honda huella en una época que va siendo patrimonio de los libros y de las viejas estampas que coleccionan los anticuarios.

Julio Jiménez Rueda. 
